\title{
The powerful self: How social power and gender influence face perception
}

\author{
Eva G. Krumhuber ${ }^{1}\left[\right.$ Xijing Wang $^{1,2} \cdot$ Ana Guinote ${ }^{1,3}$
}

Accepted: 26 January 2022

(c) The Author(s) 2022

\begin{abstract}
While ample evidence supports an association between power and dominance, little is still known about how temporary experiences of power influence the way people come to see themselves and others. The present research investigates the effect of social power on self- and other-face recognition, and examines whether gender modulates the direction of this effect. Male and female participants were induced to feel either powerful or powerless and had to recognize their own face and those of same-sex strangers from a series of images ranging from a dominant to a submissive version of the original. Results showed that males more frequently chose a dominant self-image under high power, whereas females selected a submissive self-image under low power. When presented with faces of same-sex targets female participants relied on low-power features (i.e., submissiveness) of the self in the perception of others (assimilation effect), whereas male participants more often selected a dominant image of strangers when feeling powerless (constrast effect). The effects of power did not extend to more deliberate judgments of dominance and likability, suggesting that respective biases in face recollection operated at an implicit level. This research underscores the cognitive and motivational underpinnings of power and related gender gaps in power attainment.
\end{abstract}

Keywords Social power $\cdot$ Gender $\cdot$ Face recognition $\cdot$ Dominance

\section{Introduction}

The ability to detect one's own face has been regarded as a precursor to self-awareness (Keenan et al., 2003) and is a core component for identity recognition (Bruce \& Young, 1986). Identifying self and other faces entails the matching of structural and configural aspects of a seen face to an internal representation in memory (Tanaka \& Sengco, 1997). Although people generally show high expertise in processing faces relative to other categories of stimuli (Tong \& Nakayama, 1999), existing evidence suggests that face memory is not static but can be subject to systematic biases (e.g., Balcetis \& Dunning, 2006; Hugenberg et al., 2011).

Eva G. Krumhuber

e.krumhuber@ucl.ac.uk

1 Present Address: Department of Experimental Psychology, University College London, 26 Bedford Way, London WC1H 0AP, UK

2 Department of Social and Behavioural Sciences, City University of Hong Kong, Hong Kong, Hong Kong

3 Instituto Universitário de Lisboa, Lisbon, Portugal
Such memory distortions do not necessarily derive from a lack of information or perceptual deficits at encoding. In the context of one's self-image, for example, facial features are personally known and readily observable on a daily basis. Instead, cognitive and motivational processes may play a crucial role in the recollection of self- and other-faces.

There is growing evidence that top-down factors (i.e., beliefs, desires, contexts, and motives) influence how faces are perceived and remembered (Hugenberg \& Wilson, 2013). Those often serve a preparatory function in determining what people expect to see in a face in the first place. For example, studies have shown that unfamiliar faces are preferred and evaluated more positively when they resemble one's own face (Bailenson et al., 2008; DeBruine, 2005). In a similar vein, individuals are more likely to recognize themselves in faces that are attractive and trustworthy than the reverse (Epley \& Whitchurch, 2008; Verosky \& Todorov, 2010). While self-enhancement effects are well established in the literature, little is still known about whether socialcontextual factors, such as one's standing in social relations, lead to biased perceptions and distortions in self- and otherface recognition. The present research aims to address this 
issue by examining the role of social power and gender in how people come to see themselves and others.

\section{Power and dominance}

According to Fiske's power-as-control theory (1993), social power provides asymmetrical control by giving individuals the capacity to influence others and to change their thoughts, feelings, and behavior in meaningful ways (Keltner et al., 2003). Across species individuals who are more influential typically have distinctive biomarkers, such as increased testosterone levels (i.e., a hormone linked to an individual's dominance disposition and implicit power motivation, Mazur \& Booth, 1998; Stanton \& Schultheiss, 2009) and physical strength (Sell et al., 2009). In humans, social power has been shown to affect a variety of cognitive processes, motivation, and behavior. Power triggers approach motivation and goal-driven behavior (Galinsky et al., 2003; Guinote, 2017; Keltner et al., 2003), as well as cognitive flexibility (Guinote, 2007; Overbeck \& Park, 2006) and efficiency (Lin et al., 2021). Power holders readily intervene and seize opportunities to have a social impact. This includes speaking more and more loudly, successfully interrupting conversations (Hall et al., 2005; Ko et al., 2015), and being the first to make an offer in negotiations (Magee et al., 2007).

The greater agency of power holders requires effort and physical formidability. Hence, individuals who are formidable tend to be afforded power by others, regardless of whether they are male or female (Blaker et al., 2013; Brown et al., 2021). Not surprisingly, social power is often inferred via physical features that indicate formidability (e.g., height and muscularity; Blaker et al., 2013; Chen et al., 2021). Of particular importance is facial dominance, associated with characteristics such as a prominent jawline, pronounced eyebrows, and thin lips (Van-Vugt \& Grabo, 2015). Those who look strong and dominant are favored as leaders and attain higher ranks in organizational settings. For example, people with dominant facial features are more likely to reach higher military rankings, achieve business success, and receive more votes in political campaigns (e.g., Alrajih \& Ward, 2014; Little et al., 2007; Mueller \& Mazur, 1996).

Whilst there is ample evidence pointing to an association between power and facial dominance (e.g., Olivola et al., 2014; Rule \& Ambady, 2008), not much work to date exists on how power affects the way people (visually) see themselves. Temporary social positions could influence how the physical self is construed. According to self-categorization theory (Turner et al., 1987), people readily assimilate their working self-concept to salient social categories (Kawakami et al., 2012). That is, they behave and judge themselves according to the norms, values, and prototypes of the social category (i.e., high/low power) shared within a society. Those categories are typically internalized via self-perception processes (Bem, 1972) and become central to how the self is construed. Also, people's active self largely varies across contexts (Wheeler et al., 2007), with certain situations or conditions (i.e., one's standing in social relations) triggering specific self-descriptions.

Assuming that psychological experiences of power fall under the influence of top-down cognitive factors, self-representations as a lower-level visual process may be biased in memory. As such, people's perceptual memory could be distorted towards the category's prototype (i.e., power), with the effect that they recall specific visual features as more typical of the category. That is, categorizations of the self as powerful or powerless could lead to category consistent accentuations in visual self-representation (Corneille et al., 2004; Wang et al., 2018). In line with this notion, it was found that high power makes participants overestimate their own height (a well-established index of dominance) by perceiving themselves as taller than they actually were (Duguid \& Goncalo, 2012).

To our knowledge only one study so far has explored the issue within the domain of face recognition. When being tasked to select their own face from an image array, Welling et al. (2016) showed that males administered with exogeneous testosterone picked a more dominant-looking image than those given a placebo. The findings clearly suggest that selfface identity recognition is malleable. However, it remains to be shown whether these effects (a) are specific to the self or apply to face recognition (i.e., other faces) more generally, (b) generalize to male as well as female faces, and (c) can be obtained by the mere presence of category labels (i.e., when being primed with a category of social power).

As a psychological resource, power affords significant control and domination in interaction with others. Also, comparisons made between self and others are frequent standards of evaluation, as proposed by social comparison theory (Festinger, 1954). Such factors might affect face recognition in different ways, leading to mirror distortions for own and other faces (Tiedens \& Fragale, 2003). That is, effects of social power are likely to differ for self- versus other-perception. As men tend to build hierarchical and unequal relationships (Pratto et al., 1997), contrasting face schemas may be activated, whereby other people are seen as complementary to (contrasting with) the self. Particularly in the context of low power/dominance, efforts to respond to power-relevant cues in the environment could increase (Sell et al., 2009). Since it is costly to make incorrect judgments of potential rivals (leading to unsuccessful agonistic encounters in the context of aggressive competition, Bernstein (1981), greater sensitivity to cues of male dominance may be adaptive, leading to contrast effects in social perception.

Supportive evidence comes from studies showing that men's own trait dominance and height are negatively correlated with the degree to which they attribute dominance 
to masculine male (but not female) faces (Watkins et al., 2010b; Watkins et al., 2010a). Specifically, less dominant and shorter men display a greater tendency to perceive male faces as more dominant. In a similar vein, high power makes men underestimate the height and weight of male targets, whereas low power has the opposite effect (Yap et al., 2013). Power and in particular the lack thereof might consequently affect other-face memory in ways that reinforces the social hierarchy, thereby resulting in dominance complementarity in the visual perception of self and others.

\section{Power and gender}

Aside from the differential effects of power on recognizing own versus other faces, the gender of the person plays an important role in determining how faces are visually represented in memory. Traditionally, power and dominance are concepts closely interlinked with masculinity (Oosterhof $\&$ Todorov, 2008). Men are seen as dominant, powerful, and prone to be leaders (Koenig et al., 2011). Compared to women, they are rated higher on agentic traits indicating authority and leadership (Pillemer et al., 2014), with power being an integral part of men's roles (Schmid Mast, 2004). This power differential translates to gender disparities in organisational hierarchies, where men exert higher levels of power and influence than women (Carli, 2001).

Not surprisingly, women are still disproportionately underrepresented in power roles such as top managerial positions. While making up $38.8 \%$ of the work force, they only hold $29 \%$ seats of senior level managers and merely $2.6 \%$ of CEOs in S\&P 500 companies (Catalyst, 2021). The situation is similar in politics where women are still far from being equally represented, holding only $25 \%$ seats of parliament worldwide (International IDEA, 2021). This underrepresentation applies to many developed countries, including the United States (27.3\%), the United Kingdom (34.2\%) and Canada (30.2\%; International IDEA, 2021). Among 72\% of female executives, gender stereotypes were acknowledged as one of the biggest obstacles faced by women in the workplace (Wellington et al., 2003). Given this imbalance, the topic of power and gender has been central to various fields such as psychology, sociology, and business.

Interestingly, women are less likely to self-identify with power (Haines \& Kray, 2005) and report lower levels of power motivation (Schuh et al., 2014). They are reluctant to identify with dominant characteristics, feel less competent, and report that they are less interested in leadership roles (Eagly \& Johnson, 1990). As a result, they are less likely to pursue jobs that enhance power inequalities (Pratto et al., 1997). These gender differences in power motivation can be largely explained by social roles traditional assigned to males and females (Carli, 1999; Heilman, 2001). According to social role theory, society has formed gender-stereotypic beliefs and idealized roles for each gender in relation to power and dominance (Koenig et al., 2011). These associate men with high status roles such as breadwinners and women with domestic/supportive roles such as homemakers (Dasgupta \& Asgari, 2004; Eagly et al., 2000; Wood \& Eagly, 2012). In consequence, femininity is regarded as gentle, empathic, and submissive; lacking in agency and power (Eagly, 1987; Eagly \& Karau, 2002).

Whilst social power is something desirable for men, it may create a backlash against women who risk negative social reactions (Eagly \& Karau, 2002). In line with this argument, female power holders are often described as 'iron maiden' and 'ice-queens' (Heilman et al., 2004), with the effect that they are judged as more hostile (e.g., devious, bitter; Heilman et al., 1995). They experience criticism and penalization from both men and women (Rudman, 1998), and are viewed as less socially skilled and feminine than their male counterparts (Rudman \& Glick, 1999; Wang et al., 2018). Also, dominant behavior and appearance fail to increase the perceived attractiveness of women, whereas they do so in men (Brescoll \& Uhlmann, 2008; Sadalla et al., 1987). In fact, female faces are rated as attractive the more submissive/immature features they contain such as a round face, large eyes, and a small chin (Keating, 1985).

Traits that serve as dominance cues for men (i.e., masculine facial features) may therefore not be appealing to women (Sutherland et al., 2015) because they violate conventions of appropriate female behavior (Eagly \& Karau, 2002). Instead, socially shared expectations that link women with submissiveness may constitute the preferred point of view (Bailey \& Kelly, 2015). This could lead to the visual representation of own faces in which the self is predominantly aligned with perceptions of low power/dominance. As women come to internalize gender-stereotypic roles, submissive traits and appearances related to the self may appear more typical and desirable.

Apart from power and status differentials between the sexes, men and women also diverge in their ways to pursue power and to influence others (Eagly et al., 2003; Wellington et al., 2003). While men are inclined to form dominance hierarchies, women are more communal and prefer to build egalitarian relationships with others (Schmid Mast, 2002). As such, they possess more democratic and participative leadership styles that have team-building character (Eagly \& Johnson, 1990). Given their greater focus on relationshipmaintaining behaviors, women may then adopt the self-concept as a reference point for perceiving others. That is, they respond in assimilative ways by relying on features related to the self in other-face recognition. Such tendency could result in assimilation effects, making them perceive other women's physiognomy as submissive (vs. dominant) and approachable; hence, similar to how they perceive themselves. 


\section{Aims of the present research}

Numerous studies have shown that power and dominance are closely interlinked. Yet little is known about how social power influences the way people come to see themselves (Duguid \& Goncalo, 2012; Welling et al., 2016). The present research aims to fill that gap by investigating the effects of social power on face recollection for self (and others). As an emblem of the self, faces are an index of personal identity, thereby providing crucial insights into people's selfconcepts. While social power has been shown to impact thoughts, feelings, and behaviors (Keltner et al., 2003), literature on the relationship between power and the self-concept (Haines \& Kray, 2005) and power and face-perception is fairly limited. The current study is one of the first attempts to explore how temporary experiences of social power affect people's visual representation of self and others. Given that power derives from social roles maintained within society (Wood \& Eagly, 2012), we think it is important to study whether identity recognition underlies motivated biases in face memory. Mainly examined within the domain of eye-witness memory (Wells et al., 2006), this knowledge proves relevant for identifying the psychological processes that influence how faces are perceived, remembered, and interpreted.

Moreover, we seek to explore whether gender modulates the direction of this effect. While gender disparities remain pronounced in largely male-defined domains of leadership (Depret \& Fiske, 1993; O’Neil et al., 2011), insights into the cognitive and motivational factors that hold women back from reaching top leadership positions are one of the most pressing issues in today's society. By allowing participants to experience temporary feelings of high/low power, we can study how men and women form implicit self-power associations and how those differ as a function of gender (Haines \& Kray, 2005). Such knowledge proves essential for developing new forms of social empowerment that increase women's access and participation by strengthening their self-identification with power.

As an individual's self-concept is constructed in relation to other people (Tatlow-Golden \& Guerin, 2017), we further think it is crucial to examine how power asymmetries translate into perceptions of same-sex strangers. To date, power differentials between the sexes have been largely studied independently from self-face recognition. With men typically trying to excel over their competitors (contrasting behaviors) and women striving toward similarity in relationships (assimilative behaviors; Schmid Mast, 2001), self-face processing may be indicative for how others are perceived. Hence, we tested whether social power leads men/women to view others as contrasting/assimilative with the self in terms of power. To that end, male and female participants were induced to feel either powerful or powerless via a recall task (Galinsky et al., 2003). In a next step, they were asked to select from a series of morphed images, ranging from a dominant to submissive category, the one that closest represents their own face or the face of three same-sex strangers.

First, we examined whether temporary experiences of social power influence self-face recognition. If power leads to a dominance bias in self-perception, participants should be more likely to choose a dominant version for their own face in conditions of high (vs. low) power (Hypothesis 1). Second, we explored whether face recognition significantly varies as a function of gender. To that end, we predicted that male participants would see themselves as more dominant under high (vs. low) power, whereas female participants would see their own facial image as more submissive under low (vs. high) power (Hypothesis 2). Third, results were expected to differ across men and women when recognizing same-sex strangers' faces. Specifically, we explored whether power affects other-face representation through contrast or assimilation effects. While power may lead men to view others as contrasting with the self (producing a hierarchical differentiation in the visual representation of other faces), women should be more prone to perceive the faces of others as similar to their own (producing assimilation effects between self- and other-perception) (Hypothesis 3).

People often rely on distinctive categorical features when retrieving information from memory. That is, they combine low-level perceptual information with top-down schematic and category information in face recognition (Hugenberg \& Sacco, 2008; Huttenlocher et al., 2000). The present research employs an implicit measure of memory bias that incorporates face morphing techniques, thereby minimizing potential demand effects. Given that face recognition occurs rapidly and intuitively (Grill-Spector \& Kanwisher, 2005), we assumed that categorical influences of social power would be specific to the visual representation of faces, but not extend to more deliberate judgments which require conscious deliberation (Hypothesis 4). To test this assumption, participants also provided explicit ratings of dominance and likability for all facial images. Furthermore, we measured participants' mood to control for potential confounds that might derive from power induction (see also Lee \& Schnall, 2014).

\section{Method}

\section{Participants}

Two hundred and thirty-three White students (120 female, $M_{\text {age }}=25.77, S D=5.79$ ), aged $18-49$ years, participated in exchange for course credit or payment of £4. Only White participants were chosen since the target faces were of this 
ethnicity, thereby avoiding potential cross-race effects (Corneille et al., 2004; Krumhuber et al., 2015).

Participants within each gender group were randomly assigned to one of the two power conditions, resulting in 62 men and 60 women in the high-power condition, and 51 men and 60 women in the low-power condition. A-priori power analysis using $\mathrm{G}^{*}$ Power 3.1 (Faul et al., 2007) indicated that this sample size was sufficient to detect medium-sized main and interaction effects of power and gender (Cohen's $f$ $=0.25$ ) in a $2 \times 2$ ANOVA (F-tests, ANOVA: Fixed effects, special, main effects and interactions), and main and interaction effects of power, gender, and morph level (Cohen's $f$ $=0.25)$ in a $2 \times 2 \times 9$ ANOVA (F-tests, ANOVA: Repeated Measures, between factors, within factors, within-between interaction) with $95 \%$ statistical power $(\alpha=0.05)$. The estimated effect sizes are similar to those obtained by Welling et al. (2016; $\mathrm{r}=.25$ or $f=0.258)$, Yap et al. (2013, Study 1: $r=.28$ or $f=0.29$ ), and Lee and Schnall (2014, Study 3: $d$ $=0.40$ or $f=0.20$ ). The study was conducted with ethical approval from the Department of Experimental Psychology at University College London, United Kingdom. All participants gave written informed consent before testing.

\section{Stimulus materials}

Each participant was photographed in frontal view and with a neutral expression under similar lighting conditions. If necessary, glasses were removed and hair pulled back to avoid occlusion. For male participants, three White male faces were selected from The Center for Vital Longevity Face Database (Minear \& Park, 2004) to serve as unfamiliar others' faces. All three male targets were matched in terms of perceived dominance $(M=3.89)$, attractiveness $(M=3.03)$, and competence $(M=3.83,7$-point scale, all $p s>0.05)$ as determined in a pilot study $(N=38)$. For female participants, three White female faces were selected from two databases (KDEF, Lundqvist et al., 1998; FERET, Phillips et al., 2000) to serve as unfamiliar others' faces. All three female targets were matched in terms of perceived dominance $(M=$ $4.00)$, attractiveness $(M=4.01)$, and competence $(M=4.19$, 7-point scale, all $p s>0.05)$ as determined in another pilot study $(N=21)$. Overall, female targets were comparable to male targets in their perceived dominance, $t(57)=0.52, p$ $=.604, d=0.07$, and competence, $t(57)=1.75, p=.085, d$ $=0.23$, but scored significantly higher than male targets in attractiveness, $t(57)=4.42, p<.001, d=0.58$.

Self-face and other-face images were edited using Adobe Photoshop to centralize the head, remove extraneous background, and crop the image so that only the face remained visible. Following established methods (e.g., Welling et al., 2013, 2016), prototype-based image transformations were used to objectively manipulate the dominant characteristics of facial images. For this, participants' own face as well as the other targets' faces were morphed with a dominant and submissive prototype using Psychomorph software (Tiddeman et al., 2001). Prototypes consisted of computer-generated faces that were averaged from a sample of 15 highly dominant (+3 SD) and submissive (-3 SD) faces developed by Oosterhof and Todorov (2008). These included variations in facial features (i.e., mouth corners, eyebrows, eye shape) that had previously been validated with respect to perceived dominance (Todorov et al., 2013; Todorov \& Oosterhof, 2011). By marking up feature points on the participants' and other targets' faces that corresponded to identical points on the prototype faces, each original image was transformed for shape in $2.5 \%$ increments (up to $10 \%$ ) towards a more dominant or submissive face (for technical details, see Tiddeman et al., 2001). Examples of dominant and submissive versions are shown in Fig. 1. This resulted in nine images for each face: four increasingly dominant morphs, the original image, and four increasingly submissive morphs. Previous research has demonstrated that this image manipulation method affects perceptions of dominance in the predicted manner (Welling et al., 2016). For the sake of simplicity, the face continuum was re-labelled using a scale from $-100 \%$ (most dominant) to $+100 \%$ (most submissive), with the original face coded as zero. The resulting 36 facial stimuli (participant's own face and 3 other faces $x 9$ variants) were displayed in color on white background and measured $323 \times 323$ pixels.

\section{Procedure}

The experiment was announced as a two-part laboratory study. When photographs were taken during the first part of the experiment, participants were shown images of three unfamiliar faces and asked to memorize them for a later recognition test. After returning to the lab within a week, participants were told that they would complete two unrelated tasks. In order to avoid suspicion of the experimental manipulation of power, they received separate information sheets and signed two different informed consent forms. Both tasks were conducted using the Qualtrics survey software.

In the first task, participants were told that the study was about 'Past Recollections', with the aim to assemble and analyze various descriptions of past events. To manipulate participants' sense of power, we employed the power induction procedure of Galinsky and colleagues (Galinsky et al., 2003), which has been used in previous studies (e.g., Duguid \& Goncalo, 2012; Lee \& Schnall, 2014; Yap et al., 


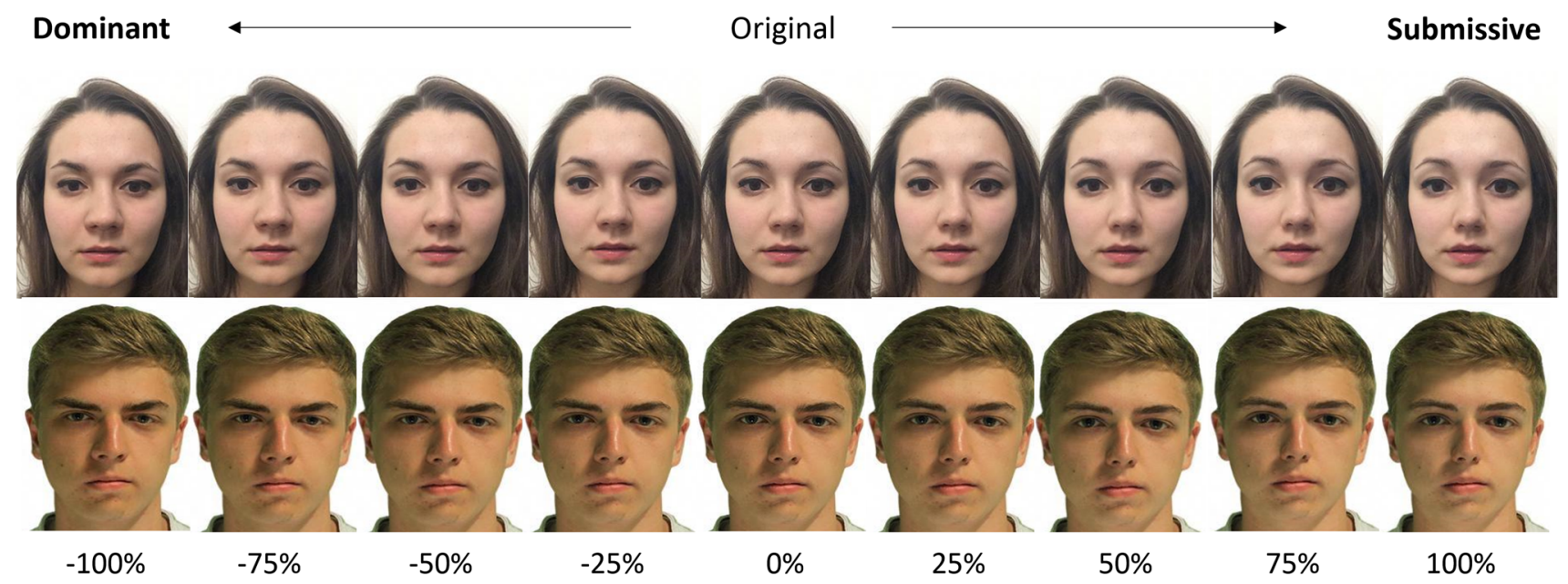

Fig. 1 Examples of a female and male participant's face with images ranging from a dominant (-100\%) to submissive (100\%) version of the original $(0 \%)$. Image order was randomized in the experiment

2013). For this, participants were instructed to recall and write 400 words (at a minimum) about a personal event from their past in which they had power over someone (high-power condition) or someone else had power over them (low-power condition). ${ }^{1}$ In both conditions, power was defined as controlling the ability of another person or persons to get something they wanted, or a position to evaluate other individuals. The manipulation conforms to the classic definition of social power as one's capacity to influence others and to change others' cognition, emotion, and behavior through rewards and punishments (Keltner et al., 2003).

\footnotetext{
1 In order to investigate whether face recognition is generally biased towards a more dominant/submissive prototype, we conducted an initial pilot study which served as the neutral (control) condition. A priori power analysis using $\mathrm{G}^{*}$ Power 3.1 indicated that a sample size of 28 per gender group was necessary to detect a medium strength effect size ( $d=0.55)$ with $80 \%$ power $(\alpha=0.05$, two-tailed) in one-sample t-tests. Bayesian analysis was conducted as an additional method of statistical inference. 30 males and 28 females $\left(M_{\text {age }}=25.47\right.$ years, $S D=6.87$ ) took part in exchange for course credit or payment of $£ 4$. None of them participated in the main study. The materials and procedure were identical to those of the main study, except that participants had to recall and write 400 words (at a minimum) about a time when they went to a supermarket and describe what they bought. When comparing recognition rates to the actual image, no memory bias was observed. Specifically, male and female participants could accurately identify their original face, $t_{\text {male }}(29)=-0.68, p=.502, d$ $=0.12$, JZS BF01 $=4.16$ (substantial evidence for H0), $t_{\text {female }}(27)=$ $0.53, p=.599, d=0.10, \mathrm{JZS} \mathrm{BF}_{01}=4.38$ (substantial evidence for $\mathrm{H} 0$ ), as well as those of others, $t_{\text {male }}(29)=-0.25, p=.804, d=0.05$, JZS $\mathrm{BF}_{01}=5.00$ (substantial evidence for $\mathrm{H} 0$ ), $t_{\text {female }}(27)=0.67$, $p=.512, d=0.13, \mathrm{JZS} \mathrm{BF}_{01}=4.07$ (substantial evidence for $\mathrm{H} 0$ ). Collectively, these findings suggest that people are generally able to recall the features of their and others' faces, and such skill does not vary with the gender of the person.
}

As a manipulation check, participants subsequently reported how much in charge they were and how much influence they had over others in the scenario described, using 9-point Likert scales ranging from 1 - not at all to 9 - very much. In addition, they also indicated their current mood ("How do you feel at this particular moment?") on a scale from 1 - very negative to 7 - very positive.

The second task was labelled as a study on 'Face Perception', with the aim to analyze how people perceive human faces. Upon reminding participants of their photographs taken earlier, they were presented with a series of images containing their actual image as well as several modified versions. Facial stimuli always depicted the real self, four increasingly dominant morphs, and four increasingly submissive morphs. Participants' task was to select the veridical image (i.e., the image they believed was their real face) out of the nine images (display resolution: $200 \times 200$ pixels) that were presented simultaneously on the screen in a random arrangement (for a similar method, see Epley \& Whitchurch, 2008; Wang et al., 2018; Welling et al., 2016; Zell \& Balcetis, 2012). Only one image could be selected, and no feedback was provided. The images remained on the screen until a selection was made, and participants could take as much time as needed to respond. The same recognition task was then performed for the three other targets whose actual images were shown together with dominant and submissive morphs. Stimulus and image order were randomized for the three targets. Following prior research (e.g., Epley \& Whitchurch, 2008; Wang et al., 2018; Welling et al., 2016), face label $(-100 \%=$ most dominant,$+100 \%=$ most submissive; $0=$ original image) was used as the recognition score, with the original face coded as zero. For instance, selecting $+50 \%$ (compared to $+25 \%$ ) indicates a larger bias towards dominance; selecting -50\% (compared to $-25 \%$ ) indicates 
a larger bias towards submissiveness; 0 corresponds to no recognition bias.

To obtain explicit face ratings, participants next viewed each of the nine images (display resolution: $323 \times 323$ pixels) again depicting themselves or the three others in isolation and judged them on two attributes: likability (1 - not at all, 7 - very much) and dominance $(1-$ very submissive, 7 - very dominant). Stimulus evaluation was blocked for each attribute, with ratings for the self always preceding those of others. The order of stimulus presentation within a block was randomized. Dominance ratings were always made last to avoid potential cueing effects.

Finally, participants were thanked and debriefed.

\section{Results}

\section{Manipulation checks}

Analyses of variance (ANOVA) were conducted, with power (high, low) and gender (male, female) entered as betweensubjects variables. The main effect of power was significant for all three dependent measures: in-charge, $F(1,229)=$ $397.22, p<.001, \eta_{\mathrm{p}}{ }^{2}=0.63$; influence, $F(1,229)=464.09$, $p<.001, \eta_{\mathrm{p}}{ }^{2}=0.67$; mood, $F(1,229)=21.86, p<.001$, $\eta_{\mathrm{p}}{ }^{2}=0.09$. There were no main effects of or interactions with gender $(F \mathrm{~s}<0.71, p \mathrm{~s}>0.401)$.

Participants in the high-power condition reported being significantly more in charge $(M=7.25, S D=1.67)$ and having more influence over others $(M=7.41, S D=1.46)$ than those in the low-power condition $(M=2.81, S D=1.72$ and $M=2.74, S D=1.82$, respectively), which indicates that the manipulation of power was successful. Participants in the high-power condition $(M=4.86, S D=1.70)$ also felt in a more positive mood than those in the low-power condition $(M=3.63, S D=1.70)$. To account for possible effects of mood, we controlled for this variable as a covariate in all subsequent analyses.

\section{Recognition scores}

Hypothesis 1 For self-recognition, a 2 (power: high, low) x 2 (gender: male, female) ANOVA revealed a significant main effect of social power, $F(1,229)=7.10, p=.008, \eta_{\mathrm{p}}{ }^{2}=0.03$, such that participants in the high-power condition chose a more dominant facial image as their own $(M=-3.69, S D=$ 41.37) than those in the low-power condition $(M=12.61$, $S D=47.78)$. There was also a significant main effect of gender, $F(1,229)=17.31, p<.001, \eta_{\mathrm{p}}{ }^{2}=0.07$, in the sense that male participants chose a more dominant facial image as their own $(M=-8.41, S D=47.79)$ than did female participants $(M=15.83, S D=39.29)$. The interaction between social power and gender was not significant, $F(1,229)=$
$0.08, p=.783, \eta_{\mathrm{p}}{ }^{2}<0.001$. Including mood as a covariate did not change the pattern of results, and there was no effect of mood, $F(1,228)=0.02, p=.883, \eta_{\mathrm{p}}^{2}<0.001$.

Hypothesis 2 To explore the extent to which estimates were accurate, one sample t-tests were conducted to compare participants' recognition rates to the actual image. While high power led men to falsely select an image that was more dominant than their original face, $M=-14.52, S D=43.55$, $t(61)=-2.63, p=.011, d=0.33$, this did not occur for males in the low power condition, $M=-0.98, S D=51.95, t(50)=$ $-0.14, p=.893, d=0.02$. The reverse occurred for females: low power led women to falsely select an image that was more submissive than their original face, $M=24.17, S D=$ $40.90, t(59)=4.58, p<.001, d=0.59$. This memory distortion was absent for female participants in the high power condition, $M=7.50, S D=36.04, t(59)=1.61, p=.112$, $d=0.21$, suggesting that they could accurately identify the veridical image of their physical self (see Fig. 2).

Hypothesis 3 Recognition scores for other faces were averaged across the three stimulus targets. A 2 (power: high, low) x 2 (gender: male, female) ANOVA revealed a significant main effect of gender, $F(1,229)=14.72, p<$ $.001, \eta_{\mathrm{p}}{ }^{2}=0.06$, such that female participants chose a more submissive image as the representation of others' face $(M$ $=12.43, S D=38.29)$ than did male participants $(M=$ $-4.65, S D=32.96)$. There was also a significant interaction between gender and social power, $F(1,229)=12.05, p$ $=.001, \eta_{\mathrm{p}}{ }^{2}=0.05$. Pairwise comparisons showed that low power led female participants to select a more submissive representation of others' face $(M=22.78, S D=33.05)$ compared to male participants $(M=-10.78, S D=30.97, p<$ $.001)$. This gender difference was not significant in the highpower condition (male: $M=0.40, S D=33.92$; female: $M=$ $2.08, S D=40.58, p=.740)$. The main effect of social power was not significant, $F(1,229)=1.07, p=.302, \eta_{\mathrm{p}}{ }^{2}<0.01$. The results remained the same when mood was entered as a covariate in the analysis, and there was no effect of mood, $F(1,228)=1.17, p=.279, \eta_{\mathrm{p}}^{2}<0.01$.

One sample t-tests were conducted to compare participants' recognition rates to the actual image. While a lack of power led men to falsely believe that the other targets' faces were more dominant than they actually were, $t(50)=-2.49, p$ $=.016, d=0.35$, the opposite trend occurred for female participants. As such, a lack of power led them to falsely believe that the other targets' faces were more submissive than they actually were, $t(59)=5.34, p<.001, d=0.69$. No such effects occurred for male and female participants in the high-power condition who correctly identified the original faces of the three targets, $t_{\text {male }}(61)=0.09, p=.926, d=$ $0.01, t_{\text {female }}(59)=0.40, p=.692, d=0.05$. 


\section{Self-recognition}

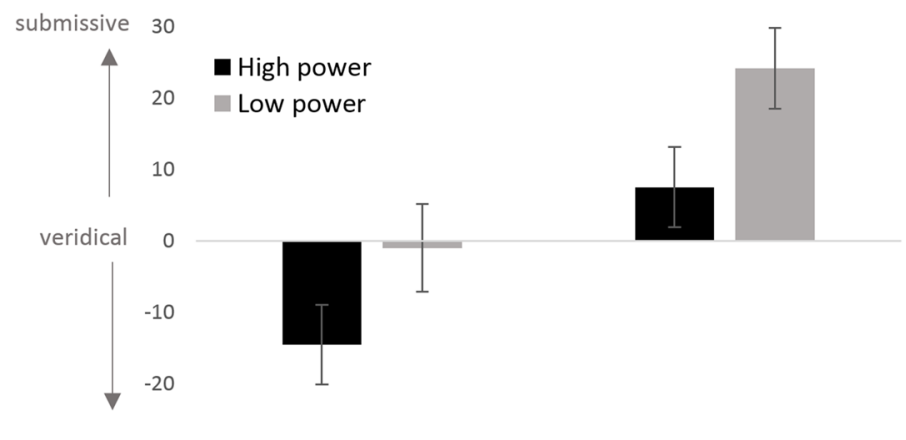

dominant -30

Male Female

Fig. 2 Mean accuracy of self- and other-recognition (-100-100\% scale) in male and female participants as a function of high vs. low power. Face recognition is reported as the mean morph level selected by participants, with positive values indicating a mean selection mor-

\section{Other-recognition}

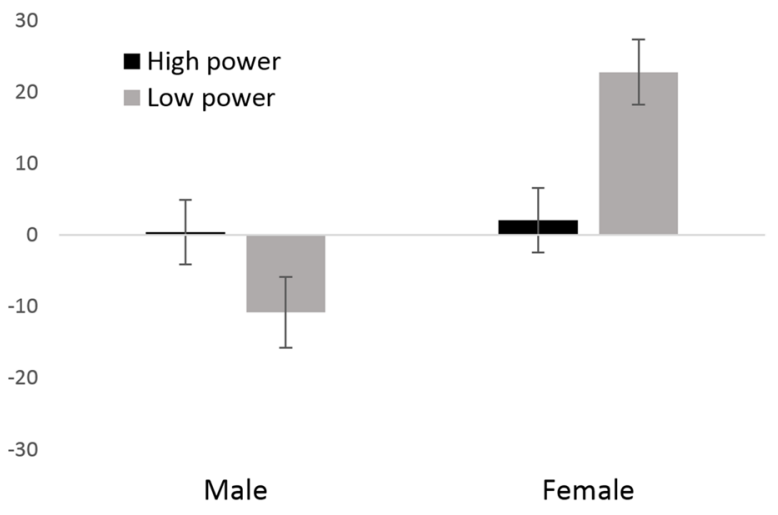

phed in the direction of the submissive target, and negative values indicating a mean selection morphed in the direction of the dominant target. Error bars represent SEM
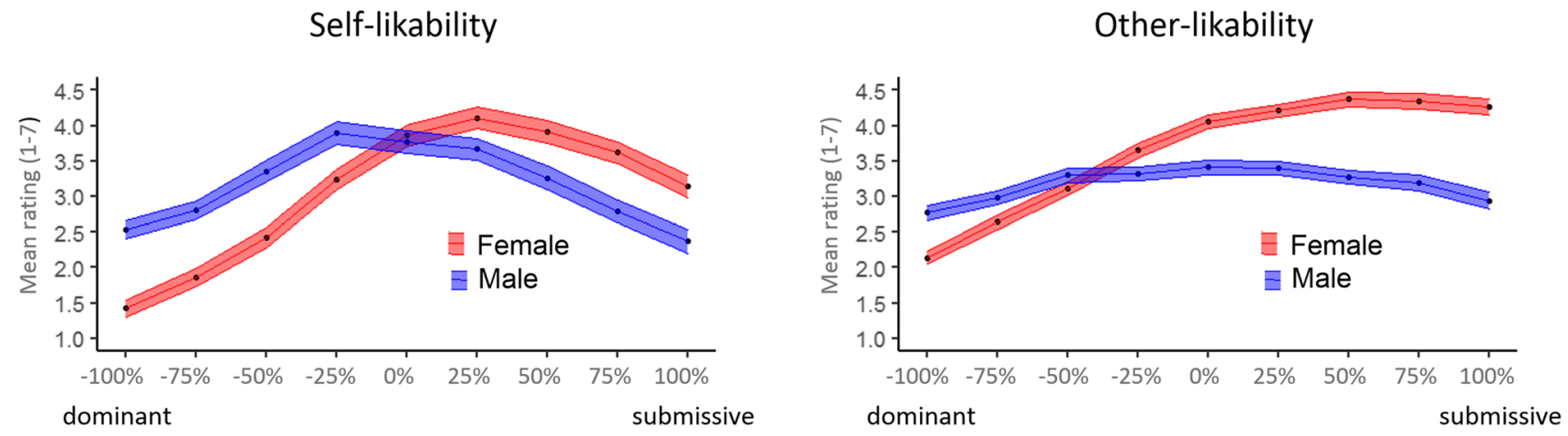

Fig. 3 Male and female participants' mean ratings of likability for self and other across the face continuum. Line width represents SEM

\section{Likability ratings}

The Greenhouse-Geisser adjustment to the degrees of freedom was applied when the assumption of sphericity was violated.

Hypothesis 4 For self-judgments of likability, a 2 (power: high, low) x 2 (gender: male, female) x 9 (morph level: $-100 \%$ to $+100 \%)$ ANOVA revealed a significant main effect of morph level, $F(4.21,964.61)=66.55, p<.001$, $\eta_{\mathrm{p}}^{2}=0.22$, as well as a significant interaction between gender and morph level, $F(4.21,964.61)=24.32, p<.001$, $\eta_{\mathrm{p}}^{2}=0.10$. Pairwise comparisons with Bonferroni correction showed that male (vs. female) participants liked more dominant facial images $(-25 \%,-50 \%,-75 \%,-100 \%, p$ s $<$ 0.01 ), whereas female (vs. male) participants liked more submissive facial images $(25 \%, 50 \%, 75 \%, 100 \%, p$ s < 0.05 , see Fig. 3). All other main and interaction effects were non-significant $(F \mathrm{~s}<1.09, p \mathrm{~s}>0.36)$. The results remained the same when mood was entered as a covariate in the analysis, and there was no effect of mood, $F(1,228)=1.81, p=$ $.180, \eta_{\mathrm{p}}^{2}=0.01$.

Judgments of likability for other faces were averaged across the three stimulus targets. A 2 (power: high, low) $\mathrm{x} 2$ (gender: male, female) x 9 (morph level: $-100 \%$ to $+100 \%$ ) ANOVA revealed significant main effects of morph level, $F(3.44,787.78)=113.96, p<.001, \eta_{\mathrm{p}}{ }^{2}=0.33$, and gender, $F(1,229)=16.57, p<.001, \eta_{\mathrm{p}}{ }^{2}=0.07$. These two main effects were qualified by a significant interaction between gender and morph level, $F(3.44,787.78)=60.52, p<.001$, $\eta_{\mathrm{p}}{ }^{2}=0.21$. Pairwise comparisons with Bonferroni correction showed that male (vs. female) participants preferred the two most dominant facial images $(-75 \%,-100 \%, p \mathrm{~s}<0.05)$, whereas female (vs. male) participants liked more the $-25 \%$ dominant image $(p=.018)$, the original image $(0 \%, p<$ 
Self-dominance

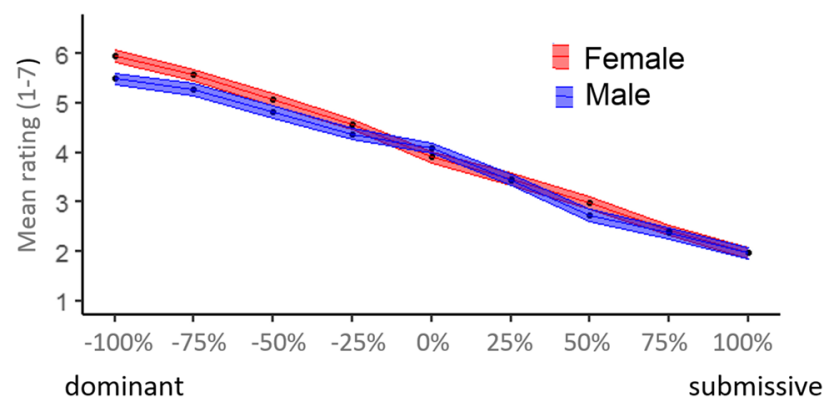

Other-dominance

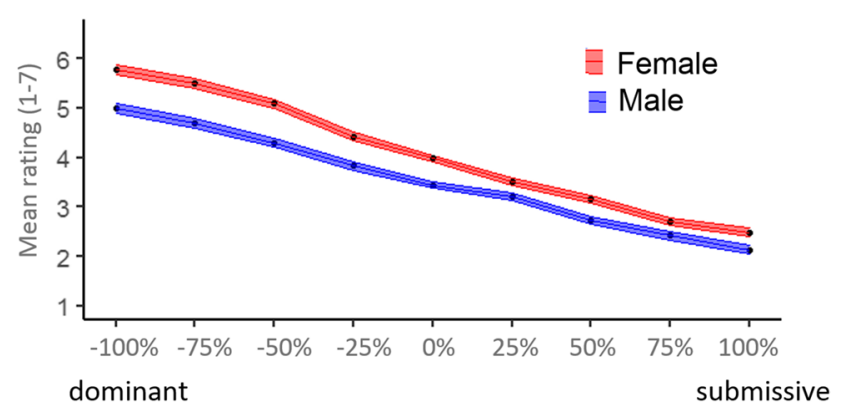

Fig. 4 Male and female participants' mean ratings of dominance for self and other across the face continuum. Line width represents SEM

$.001)$, and submissive facial images $(25 \%, 50 \%, 75 \%, 100 \%$, $p s<0.001)$. All other main and interaction effects were nonsignificant $(F \mathrm{~s}<2.05, p \mathrm{~s}>0.10)$. The results remained the same when mood was entered as a covariate in the analysis, and there was no effect of mood, $F(1,228)=0.49, p=.484$, $\eta_{\mathrm{p}}^{2}<0.01$.

\section{Dominance ratings}

The Greenhouse-Geisser adjustment to the degrees of freedom was applied when the assumption of sphericity was violated.

Hypothesis 4 For self-judgments of dominance, a 2 (power: high, low) x 2 (gender: male, female) x 9 (morph level: $-100 \%$ to $+100 \%)$ ANOVA revealed a significant main effect of morph level, $F(4.24,970.09)=377.33, p<.001$, $\eta_{\mathrm{p}}{ }^{2}=0.62$. Polynomial contrasts yielded a significant linear trend, $F(1,229)=922.73, p<.001, \eta_{\mathrm{p}}{ }^{2}=0.80$, with dominance ratings linearly increasing with higher levels of facial dominance (see Fig. 4). All other main and interaction effects were non-significant $(F \mathrm{~s}<3.57, p \mathrm{~s}>0.06)$. While the effect of mood was significant when entered as a covariate in the analysis, $F(1,228)=4.83, p=.029, \eta_{\mathrm{p}}{ }^{2}=0.02$, it did not change the pattern of statistical results.

Judgments of dominance for other faces were averaged across the three stimulus targets. A 2 (power: high, low) 2 (gender: male, female) x 9 (morph level: $-100 \%$ to $+100 \%$ ) ANOVA revealed significant main effects of morph level, $F(2.83,649.18)=533.43, p<.001, \eta_{\mathrm{p}}{ }^{2}=0.70$, and gender, $F(1,229)=45.75, p<.001, \eta_{\mathrm{p}}{ }^{2}=0.17$. These two main effects were qualified by a significant interaction between gender and morph level, $F(2.83,649.18)=4.88, p=.003$, $\eta_{\mathrm{p}}{ }^{2}=0.02$. Pairwise comparisons with Bonferroni correction showed that female (vs. male) participants rated other faces as more dominant on all morph levels (-100-100\%, ps < $0.05)$. Polynomial contrasts yielded a significant linear trend,
$F(1,229)=7.47, p=.007, \eta_{\mathrm{p}}{ }^{2}=0.03$, with dominance ratings from both male and female participants linearly increasing with higher levels of facial dominance. All other main and interaction effects were non-significant $\left(F_{\mathrm{s}}<1.37, \mathrm{ps}\right.$ $>0.24)$. The results remained the same when mood was entered as a covariate in the analysis, and there was no effect of mood, $F(1,228)=0.43, p=.511, \eta_{\mathrm{p}}^{2}<0.01$.

\section{Discussion}

The aim of this research was to investigate how social power and gender affect the way people come to see themselves and others. In line with hypothesis 1 , we found that power experiences generally led to a dominance bias in self-perception, whereby participants in the high-power condition selected an image that was more dominant in appearance than those in the low power condition. The results provide original evidence that temporary power experiences trigger distortions in social cognition that extend to face recollection (Duguid \& Goncalo, 2012; Welling et al., 2016). This shift towards a dominant physiognomy is congruent with the demands of power roles and power holders' need for formidability as they impact the social world (Brown et al., 2021; Lukaszewski et al., 2016). The finding that these memory distortions applied to a well-known and objectively verifiable feature of the self (i.e., the face) signifies the importance of one's social standing in recollecting personal attributes. More generally it highlights that own-face representations are flexible, making them prone to top-down contextual effects (Hugenberg \& Wilson, 2013).

Moreover, we observed that participants' gender influences the direction of the effects. Whilst the interaction between social power and gender turned out to be insignificant, male and female participants' estimates of face recognition were biased (i.e., deviated from $0 \%$ - the original face) in the opposite direction. In line with hypothesis 2 , high power led males to see their own faces as more dominant 
than they actually were; a mirror effect occurred for females who selected more submissive self-images under low power. Hence, when power roles align with gender-based expectations, typically associated with chronic dispositions to respond in a dominant (for males) or submissive (for females) manner (Heilman et al., 1995; Wood \& Eagly, 2012), face recognition was biased in a power congruent manner. The finding that gender disparities occurred on a relative (deviation from 0 ), but not absolute level (mean difference), highlights the specific role of power in memory distortions. To the extent that self-perception influences behavior, these biases indirectly highlight the typical ecology of men and women in power hierarchies. In doing so, they reinforce the status quo and the perceived legitimacy of such power differentials, whereby women continue to be associated with submissive characteristics.

Besides affecting how people perceive themselves, the present results show that power significantly impacts others' recognition. In line with hypothesis 3 , the observed pattern between self- and other-perception was complementary (contrasting) for men and assimilative for women in the context of same-sex targets. While female participants relied on low-power features (i.e., submissiveness) in the perception of others, male participants more often selected a dominant image of strangers when feeling powerless. Interestingly, this applied to conditions of low but not high power, suggesting that the experienced lack of power drove the asymmetric effects. In a similar vein, Lee and Schnall (2014) found that it was only the absence of power which led to an overestimation of objects' weight. Give that dominance is a competitive feature, low personal power may lead to greater sensitivity since it is maladaptive, particularly for disempowered men, to miss dominance cues in potential rivals (Sell et al., 2009). The current pattern of findings is largely consistent with perceptual biases reported in the literature, showing that low power/dominance makes men more likely to overestimate the height and weight of others and rate male faces as dominant in appearance (Watkins et al., 2010a, b; Yap et al., 2013). Such dominance complementarity could then point toward self-other differentials in face memory that reinforce the social hierarchy.

\section{Explicit ratings}

In line with hypothesis 4 , the effects of social power observed for memory retrieval did not translate to explicit judgments about faces. Regardless of power levels, participants were equally sensitive to visual changes in facial dominance, and this was particularly the case when their own faces were evaluated. Memory biases are thus unlikely to be due to perceptual deficits imposed by feelings of high vs. low power. Rather it seems that the present task based on face morphing techniques addressed more rudimentary forms of perception, thereby allowing for implicit and automatic processes to be captured (Grill-Spector \& Kanwisher, 2005). Consistent with this notion, Epley and Whitchurch (2008) found that individuals' representation of their own face was correlated with implicit but not explicit judgments of the self. Similarly, in a study by Haines and Kray (2005) exposure to social power increased implicit self-power associations, whereas explicit self-concepts of power remained unchanged. Future research might want to explore whether such dissociation between implicit and explicit measures applies more generally. To that end, deliberate forms of selfevaluation could be supplemented with other implicit tools (e.g., IAT), including measures of self-esteem to control for baseline differences in positive self-views.

In the current work, male participants liked more dominant facial images of self and others, suggesting that dominance cues are appealing when portrayed by male targets. In contrast, submissive images were preferred by female participants whose favorable perception may align with socially shared expectations that link women with submissiveness (Bailey \& Kelly, 2015; Keating, 1985). Given that dominant facial appearance is congruent with male representations and incongruent and undesirable for females (e.g. Brescoll \& Uhlmann, 2008; Wang et al., 2018), the findings suggest that socially shared expectations associated with each gender group act as cognitive and motivational top-down influences in face evaluation. Interestingly, female participants rated same-sex strangers as more dominant than themselves. This is surprising considering that male and female others' faces did not significantly differ in perceived dominance as shown in a pilot study. It is possible that comparisons with samesex strangers contributed to higher evaluations in women as a result of upward social comparison (Zell \& Balcetis, 2012).

\section{Limitations and outlook}

In the present study, only White Caucasian faces were used as stimulus material to match the ethnicity of the participants, thereby avoiding potential cross-race effects (Corneille et al., 2004; Krumhuber et al., 2015). Also, White participants only viewed same-sex targets as other faces to assess stereotypic perceptions within a gender category. Future research might examine cross-race and cross-gender effects by examining the memory for Black and White faces among White and Black participants in varied positions of power. Power increases implicit prejudice towards Black individuals (Richeson \& Ambady, 2003; Guinote et al., 2010), who typically occupy disadvantaged positions. It is possible that these biases would enter as an input in the memory for Black faces, shifting memory towards a disempowered physiognomy. 
Furthermore, it would be interesting to explore whether self- and other-recollections show perfectly consistent patterns (rather than asymmetric ones across gender categories) when they are equated on familiarity. Prior evidence suggests that people are more likely to recognize an attractively enhanced version of their own and a friend's face, but not a stranger's face (Epley \& Whitchurch, 2008; Penton-Voak et al., 2007). While the present study aimed at examining whether self-recognition biases extend to the recollection of unfamiliar others, future work could address the specific role of the self in face processing (Gillihan \& Farah, 2005).

In this context, the inclusion of self-esteem measures may prove valuable. Power acquisition can be considered as a mechanism of self-enhancement in the sense that it increases self-esteem (Wojciszke \& Struzynska-Kjalowicz, 2007). Given that women generally score lower on appearance selfesteem than men (Fredrickson \& Roberts, 1997; Pliner et al., 1990), it is possible that women in the powerless condition experienced decreased self-esteem, which in turn lowered their self-power associations. Future studies should also take participants' power motivation and sex role attitudes into consideration. To the extent that women consider social power and dominance as undesirable and favor traditional gender roles, they may identify less with high-power roles.

The present research adopted a power-writing paradigm in which powerful or powerless feelings were induced temporarily. Although this short-term power manipulation was successful, it is important to highlight its limitation in evoking situational (but not chronic) social power. Further work is needed to adopt a more elaborate induction procedure that allows participants to directly experience power, such as in role play tasks (Anderson \& Berdahl, 2002; Galinsky et al., 2003; Lammers et al., 2008). This could be achieved, for example, using virtual reality tools that give participants the opportunity to see themselves in a powerful position (e.g., as a manager in a company embodied through an avatar in an online virtual world). By enabling individuals to experience a realistic simulation of organizational power, power motivations may be fostered in a more long-term manner (Krumhuber et al., 2018).

\section{Implications}

The findings obtained in this work have important implications for practice and society. Until now, women have been disproportionately underrepresented in power roles such as top managerial positions (Center for American Women and Politics, 2013). A great deal of research has explained gender gaps through a glass ceiling, that is, as a result of prejudice and environmental obstacles faced by women (e.g., role congruity theory, Eagly \& Karau, 2002; lack-of-fit model, Heilman \& Caleo, 2018). Although those certainly play an important role, the present study is consistent with accounts that emphasize self-selection processes.

It is well established that gender groups differ in their values related to power (Schwartz \& Rubel, 2005). While status, prestige, control over others and resources are valued more by men, women consider benevolence and universalism (i.e., a concern with the welfare of others) as important aspects in their life (Eagly et al., 2000; Van Engen \& Willemsen, 2004). These differences in values between gender groups contribute to the maintenance of the status quo, with women actively perceiving themselves as a better fit into subordinate roles, and men into power roles (Pratto et al., 1997). As such, women's submissive self-face schemas as shown in this research could have a self-perpetuating function that may prevent them from taking on power-related roles. In contrast, dominant self-face schemas held by men may be automatically activated when opportunities arise to acquire or maintain power (Wellington et al., 2003). These self-selection processes then complement environmental pressures and social discrimination (Meyerson \& Fletcher, 2000).

The present research highlights the importance of powergender physical prototypes and their role in self-perception. Such finding along with previous evidence regarding stereotype reduction (Dasgupta \& Asgari, 2004; Finnegan et al., 2015) paves the way to drive interventions that may alleviate chronic perceptions of low power and self-confidence. To this end, it is essential to create societal awareness and to establish counter-stereotypes in education and at the workplace through varied social roles. Additionally, social connection proves relevant for driving change. Similar to women, individuals who lack power prefer communal strategies rather than confrontation (Guinote \& Lammers, 2017). In seeking social closeness to other individuals, people in powerless positions can restore, control and form coalitions that protect them against power abuse. Such approach is of societal relevance, contributing to increased gender equality and an individual's well-being in the long-term.

\section{Conclusions}

The present research contributes to the growing body of evidence suggesting that face recognition is subject to multiple influences (e.g., Balcetis \& Dunning, 2006; Hugenberg et al., 2011). Rather than retrieving a stable representation of facial shape and configuration from memory, those mental pictures of self and others are inherently flexible. We demonstrated that higher-order factors such as experiential power and chronic gender roles jointly and critically shape face representation. Whether and to what extent such biased representations translate into stereotype-consistent behavior beyond perceptual evaluations remains a much-needed topic for future research. 
Acknowledgements We would like to thank Simona Daugnoraite, Andrew Davey, Nadyne Dunkley, Alexandra Kalogeropoulo, Xinyi Pan, Brenda Shen, Tsz Siu, and Busra Yaman for their help with data collection; Chikara Ono for his help with developing the stimulus material; and Olivier Corneille for valuable comments on an earlier draft of this manuscript.

Funding This work was partly supported by a UCL Grand Challenges small grant (156425) to the first author, and a Daedalus Trust grant (520180 F67) to the third author.

Data Availability Raw data were generated at University College London. Derived data supporting the findings of this study are available from the corresponding author on request.

\section{Declarations}

Ethics Approval All procedures performed in studies involving human participants were in accordance with the ethical standards of the institutional research committee and with the 1964 Helsinki Declaration and its later amendments or comparable ethical standards. Ethical approval was granted by the ethics committee at the Department of Experimental Psychology, University College London.

Conflicts of Interest The authors declare that they have no conflict of interest.

Consent to Participate Informed consent was obtained from all individual adult participants included in the study.

Open Access This article is licensed under a Creative Commons Attribution 4.0 International License, which permits use, sharing, adaptation, distribution and reproduction in any medium or format, as long as you give appropriate credit to the original author(s) and the source, provide a link to the Creative Commons licence, and indicate if changes were made. The images or other third party material in this article are included in the article's Creative Commons licence, unless indicated otherwise in a credit line to the material. If material is not included in the article's Creative Commons licence and your intended use is not permitted by statutory regulation or exceeds the permitted use, you will need to obtain permission directly from the copyright holder. To view a copy of this licence, visit http://creativecommons.org/licenses/by/4.0/.

\section{References}

Alrajih, S., \& Ward, J. (2014). Increased facial width-to-height ratio and perceived dominance in the faces of the UK's leading business leaders. British Journal of Psychology, 105, 153-161. https://doi.org/10.1111/bjop.12035

Anderson, C., \& Berdahl, J. L. (2002). The experience of power: Examining the effects of power on approach and inhibition tendencies. Journal of Personality and Social Psychology, 83, 1362-1377. https://doi.org/10.1037/0022-3514.83.6.1362

Bailenson, J. N., Iyengar, S., Yee, N., \& Collins, N. A. (2008). Facial similarity between voters and candidates causes influence. $P u b$ lic Opinion Quarterly, 72, 935-961. https://doi.org/10.1093/poq/ nfn064

Bailey, A. H., \& Kelly, S. D. (2015). Picture power: Gender versus body language in perceived status. Journal of Nonverbal Behavior, 39, 317-337. https://doi.org/10.1007/s10919-015-0212-x
Balcetis, E., \& Dunning, D. (2006). See what you want to see: Motivational influences on visual perception. Journal of Personality and Social Psychology, 91, 612-625. https://doi.org/10.1037/ 0022-3514.91.4.612

Bem, D. J. (1972). Constructing cross-situational consistencies in behavior: Some thoughts on Alker's critique of Mischel. Journal of Personality, 40, 17-26. https://doi.org/10.1111/j.1467-6494. 1972.tb00645.x

Bernstein, I. S. (1981). Dominance: The baby and the bathwater. Behavioral and Brain Sciences, 4, 419-457. https://doi.org/10. 1017/S0140525X00009614

Blaker, N. M., Rompa, I., Dessing, I. H., Vriend, A. F., Herschberg, C., \& Van Vugt, M. (2013). The height leadership advantage in men and women: Testing evolutionary psychology predictions about the perceptions of tall leaders. Group Processes \& Intergroup Relations, 16, 17-27. https://doi.org/10.1177/1368430212 437211

Brescoll, V. L., \& Uhlmann, E. L. (2008). Can an angry woman get ahead? Status conferral, gender, and expression of emotion in the workplace. Psychological Science, 19, 268-275. https://doi.org/ 10.1111/j.1467-9280.2008.02079.x

Brown, M., Chua, K. J., \& Lukaszewski, A. W. (2021). Formidability and socioeconomic status uniquely predict militancy and political moral foundations. Personality and Individual Differences, 168 , 110284. https://doi.org/10.1016/j.paid.2020.110284

Bruce, V., \& Young, A. (1986). Understanding face recognition. British Journal of Psychology, 77, 305-327. https://doi.org/10.1111/j. 2044-8295.1986.tb02199.x

Carli, L. L. (1999). Gender, interpersonal power, and social influence. Journal of Social Issues, 55, 81-99. https://doi.org/10.1111/ 0022-4537.00106

Carli, L. L. (2001). Gender and social influence. Journal of Social Issues, 57, 725-741. https://doi.org/10.1111/0022-4537.00238

Catalyst (2021). List: Women CEOs of the S\&P 500. Catalyst

CAWP. Center for American Women and Politics (2013). Retrieved from https://cawp.rutgers.edu/

Chen, H., Wang, X., Zang, H., \& Guinote, A. (2021). Being a tough person in a tight world: Cultural tightness leads to a desire for muscularity. Journal of Experimental Social Psychology, 96, 104183

Corneille, O., Huart, J., Becquart, E., \& Brédart, S. (2004). When memory shifts toward more typical category exemplars: accentuation effects in the recollection of ethnically ambiguous faces. Journal of Personality and Social Psychology, 86, 236-250. https://doi.org/10.1037/0022-3514.86.2.236

Dasgupta, N., \& Asgari, S. (2004). Seeing is believing: Exposure to counterstereotypic women leaders and its effect on the malleability of automatic gender stereotyping. Journal of Experimental Social Psychology, 40, 642-658. https://doi.org/10.1016/j.jesp. 2004.02.003

DeBruine, L. M. (2005). Trustworthy but not lust-worthy: Contextspecific effects of facial resemblance. Proceedings of the Royal Society B: Biological Sciences, 272, 919-922. https://doi.org/10. 1098/rspb.2004.3003

Dépret, E., \& Fiske, S. T. (1993). Social Cognition and Power: Some cognitive consequences of social structure as a source of control deprivation. In G. Weary, F. Gleicher, \& K. L. Marsh (Eds.), Control Motivation and Social Cognition (pp. 176-202). Springer. https://doi.org/10.1007/978-1-4613-8309-3_7

Duguid, M. M., \& Goncalo, J. A. (2012). Living large: The powerful overestimate their own height. Psychological Science, 23, 36-40. https://doi.org/10.1177/0956797611422915

Eagly, A. H. (1987). Sex differences in social behavior: A social-role interpretation. Lawrence Erlbaum Associates

Eagly, A. H., Johannesen-Schmidt, M., \& van Engen, M. L. (2003). Transformational, transactional, and laissez-faire leadership 
styles: A meta-analysis comparing women and men. Psychological Bulletin, 129, 569-591. https://doi.org/10.1037/0033-2909. 129.4.569

Eagly, A. H., \& Johnson, B. T. (1990). Gender and leadership style: A meta-analysis. Psychological Bulletin, 108, 233-256. https://doi. org/10.1037/0033-2909.108.2.233

Eagly, A. H., \& Karau, S. J. (2002). Role congruity theory of prejudice toward female leaders. Psychological Review, 109, 573-598. https://doi.org/10.1037/0033-295x.109.3.573

Eagly, A. H., Wood, W., \& Diekman, A. B. (2000). Social role theory of sex differences and similarities: A current appraisal. In T. Eckes \& H. M. Trautner (Eds.), The developmental social psychology of gender (pp. 123-174). Lawrence Erlbaum Associates

Epley, N., \& Whitchurch, E. (2008). Mirror, mirror on the wall: Enhancement in self- recognition. Personality and Social Psychology Bulletin, 34, 1159-1170. https://doi.org/10.1177/01461 67208318601

Faul, F., Erdfelder, E., Lang, A. G., \& Buchner, A. (2007). G* power 3: A flexible statistical power analysis program for the social, behavioral, and biomedical sciences. Behavior Research Methods, 39, 175-191. https://doi.org/10.3758/BF03193146

Festinger, L. (1954). A theory of social comparison processes. Human Relations, 7, 117-140. https://doi.org/10.1177/00187 2675400700202

Finnegan, E., Oakhill, J., \& Garnham, A. (2015). Counter-stereotypical pictures as a strategy for overcoming spontaneous gender stereotypes. Frontiers in Psychology, 6, 15. https://doi.org/10. 3389/fpsyg.2015.01291

Fiske, S. T. (1993). Controlling other people: The impact of power on stereotyping. American Psychologist, 48, 621-628. https:// doi.org/10.1037/0003-066X.48.6.621

Fredrickson, B. L., \& Roberts, T. (1997). Objectification theory: Toward understanding women's lived experiences and mental health risks. Psychology of Women Quarterly, 21, 173-206. https://doi.org/10.1111/j.1471-6402.1997.tb00108.x

Galinsky, A. D., Gruenfeld, D. H., \& Magee, J. C. (2003). From power to action. Journal of Personality and Social Psychology, 85, 453-466. https://doi.org/10.1037/0022-3514.85.3.453

Gillihan, S. J., \& Farah, M. J. (2005). Is self special? A critical review of evidence from experimental psychology and cognitive neuroscience. Psychological Bulletin, 131, 76-97. https:// doi.org/10.1037/0033-2909.131.1.76

Grill-Spector, K., \& Kanwisher, N. (2005). Visual recognition: As soon as you know it is there, you know what it is. Psychological Science, 16, 152-160. https://doi.org/10.1111/j.0956-7976. 2005.00796.x

Guinote, A. (2007). Power and goal pursuit. Personality and Social Psychology Bulletin, 33(8), 1076-1087. https://doi.org/10.1177/ 0146167207301011

Guinote, A. (2017). How power affects people: Activating, wanting, and goal seeking. Annual Review of Psychology, 68, 353-381. https://doi.org/10.1146/annurev-psych-010416-044153

Guinote, A., \& Lammers, J. (2017). Accentuation of tending and befriending among the powerless. In M. Bukowski, I. Fritsche, A. Guinote, \& M. Kofta (Eds.), Coping with lack of control in a social world; coping with lack of control in a social world (pp. 185-202, Chapter IX). Routledge/Taylor \& Francis Group

Guinote, A., Willis, G. B., \& Martellotta, C. (2010). Social power increases implicit prejudice. Journal of Experimental Social Psychology, 46, 299-307. https://doi.org/10.1016/j.jesp.2009.11.012

Haines, E. L., \& Kray, L. J. (2005). Self-power associations: the possession of power impacts women's self-concepts. European Journal of Social Psychology, 35, 643-662. https://doi.org/10.1002/ejsp. 252

Hall, J. A., Coats, E. J., \& LeBeau, L. S. (2005). Nonverbal behavior and the vertical dimension of social relations: A meta-analysis.
Psychological Bulletin, 131, 898-924. https://doi.org/10.1037/ 0033-2909.131.6.898

Heilman, M. E. (2001). Description and prescription: How gender stereotypes prevent women's ascent up the organizational ladder. Journal of Social Issues, 57, 657-674. https://doi.org/10.1111/ 0022-4537.00234

Heilman, M. E., Block, C. J., \& Martell, R. F. (1995). Sex stereotypes: Do they influence perceptions of managers? Journal of Social Behavior \& Personality, 10, 237-252

Heilman, M. E., \& Caleo, S. (2018). Combatting gender discrimination: A lack of fit framework. Group Processes \& Intergroup Relations, 21, 725-744. https://doi.org/10.1177/1368430218 761587

Heilman, M. E., Wallen, A. S., Fuchs, D., \& Tamkins, M. M. (2004). Penalties for success: Reactions to women who succeed at male gender-typed tasks. Journal of Applied Psychology, 89, 416-427. https://doi.org/10.1037/0021-9010.89.3.416

Hugenberg, K., \& Sacco, D. F. (2008). Social categorization and stereotyping:How social categorization biases person perception and face memory. Social and Personality Psychology Compass, 2, 1052-1072. https://doi.org/10.1111/j.1751-9004.2008.00090.x

Hugenberg, K., \& Wilson, J. P. (2013). Faces are central to social cognition. In D. Carlston (Ed.), Handbook of social cognition (pp. 167-193). Oxford University Press

Hugenberg, K., Young, S. G., Sacco, D. F., \& Bernstein, M. J. (2011). Social categorization influences face perception and memory. In G. Rhodes, A. Calder, M. Johnson, \& J. V. Haxby (Eds.), Oxford handbook of face perception (pp. 245-262). Oxford University Press. https://doi.org/10.1093/oxfordhb/9780199559053.013. 0013

Huttenlocher, J., Hedges, L. V., \& Vevea, J. L. (2000). Why do categories affect stimulus judgment? Journal of Experimental Psychology: General, 129, 220-241. https://doi.org/10.1037/0096-3445. 129.2.220

International Institute for Democracy and Electoral Assistance (November, 2021). Global state of democracy report 2021. Retrieved from https://www.idea.int/gsod-events

Kawakami, K., Phills, C. E., Greenwald, A. G., Simard, D., Pontiero, J., Brnjas, A. ... Dovidio, J. F. (2012). In perfect harmony: Synchronizing the self to activated social categories. Journal of Personality and Social Psychology, 102, 562-575. https://doi.org/ $10.1037 / \mathrm{a} 0025970$

Keating, C. F. (1985). Gender and the physiognomy of dominance and attractiveness. Social Psychology Quarterly, 48, 61-70. https:// doi.org/10.2307/3033782

Keenan, J. P., Gallup, G. G., \& Falk, D. (2003). The face in the mirror: The search for the origins of consciousness. HarperCollins Publishers

Keltner, D., Gruenfeld, D. H., \& Anderson, C. (2003). Power, approach, and inhibition. Psychological Review, 110, 265-284. https://doi. org/10.1037/0033-295x.110.2.265

Ko, S. J., Sadler, M. S., \& Galinsky, A. D. (2015). The sound of power: Conveying and detecting hierarchical rank through voice. Psychological Science, 26, 3-14. https://doi.org/10.1177/09567 97614553009

Koenig, A. M., Eagly, A. H., Mitchell, A. A., \& Ristikari, T. (2011). Are leader stereotypes masculine? A meta-analysis of three research paradigms. Psychological Bulletin, 137, 616-642. https://doi.org/10.1037/a0023557

Krumhuber, E. G., Swiderska, A., Tsankova, E., Kamble, S. V., \& Kappas, A. (2015). Real or artificial? Intergroup biases in mind perception in a cross-cultural perspective. PLoS One, 10, e0137840. https://doi.org/10.1371/journal.pone.0137840

Krumhuber, E. G., Tzur, S., Drummond, J., \& Steed, S. (2018). Effects of social power on women's self-concept and self-face 
recognition. Poster presented at the Seventh European Conference on Emotion (CERE), Glasgow, UK (April)

Lammers, J., Galinsky, A. D., Gordijn, E. H., \& Otten, S. (2008). Illegitimacy moderates the effects of power on approach. Psychological Science, 19, 558-564. https://doi.org/10.1111/j.1467-9280. 2008.02123.x

Lee, E. H., \& Schnall, S. (2014). The influence of social power on weight perception. Journal of Experimental Psychology: General, 143, 1719-1725. https://doi.org/10.1037/a0035699

Lin, E., Freydefont, L., \& Schmid, P. C. (2021). Psychological power alters cognitive efficiency. Psychophysiology, 58(4). https://doi. org/10.1111/psyp.13773

Little, A. C., Burriss, R. P., Jones, B. C., \& Roberts, S. C. (2007). Facial appearance affects voting decisions. Evolution and Human Behavior, 28, 18-27. https://doi.org/10.1016/j.evolhumbehav. 2006.09.002

Lukaszewski, A. W., Simmons, Z. L., Anderson, C., \& Roney, J. R. (2016). The role of physical formidability in human social status allocation. Journal of Personality and Social Psychology, 110, 385-406. https://doi.org/10.1037/pspi0000042

Lundqvist, D., Flykt, A., \& Öhman, A. (1998). The Karolinska Directed Emotional Faces - KDEF, CD ROM from Department of Clinical Neuroscience, Psychology section, Karolinska Institute, ISBN 91-630-7164-9

Magee, J. C., Galinsky, A. D., \& Gruenfeld, D. H. (2007). Power, propensity to negotiate, and moving first in competitive interactions. Personality and Social Psychology Bulletin, 33, 200212. https://doi.org/10.1177/0146167206294413

Mazur, A., \& Booth, A. (1998). Testosterone and dominance in men. Behavioral and Brain Sciences, 21, 353-363. https://doi.org/ 10.1017/S0140525X98001228

Meyerson, D. E., \& Fletcher, J. (2000). A modest manifesto for shattering the glass ceiling. Harvard Business Review, 78, 126-136

Minear, M., \& Park, D. C. (2004). A lifespan database of adult facial stimuli. Behavior Research Methods, Instruments, \& Computers, 36, 630-633. https://doi.org/10.3758/BF03206543

Mueller, U., \& Mazur, A. (1996). Facial dominance of West Point cadets as a predictor of later military rank. Social Forces, 74, 823-850. https://doi.org/10.2307/2580383

Olivola, C. Y., Funk, F., \& Todorov, A. (2014). Social attributions from faces bias human choices. Trends in Cognitive Sciences, 18, 566-570. https://doi.org/10.1016/j.tics.2014.09.007

Oosterhof, N. N., \& Todorov, A. (2008). The functional basis of face evaluation. Proceedings of the National Academy of Sciences, 105, 11087-11092. https://doi.org/10.1073/pnas.0805664105

O’Neil, D. A., Hopkins, M. M., \& Sullivan, S. E. (2011). Do women's networks help advance women's careers?: Differences in perceptions of female workers and top leadership. The Career Development International, 16, 733-754. https://doi.org/10. 1108/13620431111187317

Pillemer, J., Graham, E. R., \& Burke, D. M. (2014). The face says it all: CEOs, gender, and predicting corporate performance. Leadership Quarterly, 25, 855-864. https://doi.org/10.1016/j. leaqua.2014.07.002

Overbeck, J. R., \& Park, B. (2006). Powerful perceivers, powerless objects: Flexibility of powerholders' social attention. Organizational Behavior and Human Decision Processes, 99(2), 227-243. https://doi.org/10.1016/j.obhdp.2005.10.003

Penton-Voak, I., Rowe, A., \& Williams, J. (2007). Through rosetinted glasses: Relationship satisfaction and representations of partners' facial attractiveness. Journal of Evolutionary Psychology, 5, 169-181. https://doi.org/10.1556/JEP.2007.1021

Phillips, P. J., Moon, H., Rauss, P. J., \& Rizvi, S. (2000). The FERET evaluation methodology for face recognition algorithms. IEEE Transactions on Pattern Analysis and Machine Intelligence, 22, 1090-1104. https://doi.org/10.1109/34.879790
Pliner, P., Chaiken, S., \& Flett, G. L. (1990). Gender differences in concern with body weight and physical appearance over the life span. Personality and Social Psychology Bulletin, 16, 263-273. https://doi.org/10.1177/0146167290162007

Pratto, F., Stallworth, L. M., Sidanius, J., \& Siers, B. (1997). The gender gap in occupational role attainment: a social dominance approach. Journal of Personality and Social Psychology, 72, 37-53. https://doi.org/10.1037//0022-3514.72.1.37

Richeson, J. A., \& Ambady, N. (2003). Effects of situational power on automatic racial prejudice. Journal of Experimental Social Psychology, 39, 177-183. https://doi.org/10.1016/S00221031(02)00521-8

Rudman, L. A. (1998). Self-promotion as a risk factor for women: The costs and benefits of counterstereotypical impression management. Journal of Personality and Social Psychology, 74(3), 629-645. https://doi.org/10.1037/0022-3514.74.3.629

Rudman, L. A., \& Glick, P. (1999). Feminized management and backlash toward agentic women: The hidden costs to women of a kinder, gentler image of middle managers. Journal of Personality and Social Psychology, 77, 1004-1010. https://doi.org/10.1037/ 0022-3514.77.5.1004

Rule, N. O., \& Ambady, N. (2008). The face of success: Inferences from chief executive officers' appearance predict company profits. Psychological Science, 19, 109-111. https://doi.org/10. 1111/j.1467-9280.2008.02054.x

Sadalla, E. K., Kenrick, D. T., \& Vershure, B. (1987). Dominance and heterosexual attraction. Journal of Personality and Social Psychology, 52, 730-738. https://doi.org/10.1037/0022-3514. 52.4 .730

Schmid Mast, M. (2001). Gender differences and similarities in dominance hierarchies in same-gender groups based on speaking time. Sex Roles: A Journal of Research, 44, 537-556. https://doi.org/ 10.1023/A:1012239024732

Schmid Mast, M. S. (2002). Female dominance hierarchies: Are they any different from males'? Personality and Social Psychology Bulletin, 28, 29-39. https://doi.org/10.1177/0146167202281003

Schmid Mast, M. (2004). Men are hierarchical, women are egalitarian: An implicit gender stereotype. Swiss Journal of Psychology, 63, 107-111. https://doi.org/10.1024/1421-0185.63.2.107

Schuh, S. C., Bark, H., Van Quaquebeke, A. S., Hossiep, N., Frieg, R., \& Van Dick, R. (2014). Gender differences in leadership role occupancy: The mediating role of power motivation. Journal of Business Ethics, 120, 363-379. https://doi.org/10.1007/ s10551-013-1663-9

Schwartz, S. H., \& Rubel, T. (2005). Sex differences in value priorities: Cross-cultural and multimethod studies. Journal of Personality and Social Psychology, 89(6), 1010-1028. https://doi.org/10. 1037/0022-3514.89.6.1010

Sell, A., Cosmides, L., Tooby, J., Sznycer, D., von Rueden, C., \& Gurven, M. (2009). Human adaptations for the visual assessment of strength and fighting ability from the body and face. Proceedings of the Royal Society B: Biological Sciences, 276, 575-584. https://doi.org/10.1098/rspb.2008.1177

Stanton, S. J., \& Schultheiss, O. C. (2009). The hormonal correlates of implicit power motivation. Journal of Research in Personality, 43, 942-949. https://doi.org/10.1016/j.jrp.2009.04.001

Sutherland, C. A., Young, A. W., Mootz, C. A., \& Oldmeadow, J. A. (2015). Face gender and stereo typicality influence facial trait evaluation: Counter-stereotypical female faces are negatively evaluated. British Journal of Psychology, 106, 186-208. https:// doi.org/10.1111/bjop.12085

Tanaka, J. W., \& Sengco, J. A. (1997). Features and their configuration in face recognition. Memory and Cognition, 25, 583-592. https:// doi.org/10.3758/BF03211301

Tatlow-Golden, M., \& Guerin, S. (2017). Who I am: The meaning of early adolescents' most valued activities and relationships, 
and implications for self-concept research. The Journal of Early Adolescence, 37, 236-266. https://doi.org/10.1177/0272431615 599064

Tiedens, L. Z., \& Fragale, A. R. (2003). Power moves: Complementarity in dominant and submissive nonverbal behavior. Journal of Personality and Social Psychology, 84, 558-568. https://doi.org/ 10.1037/0022-3514.84.3.558

Tiddeman, B., Burt, M., \& Perrett, D. (2001). Prototyping and transforming facial textures for perception research. Computer Graphics and Applications, IEEE, 21, 42-50. https://doi.org/10.1109/ 38.946630

Todorov, A., Dotsch, R., Porter, J. M., Oosterhof, N. N., \& Falvello, V. B. (2013). Validation of data-driven computational models of social perception of faces. Emotion, 13, 724-738. https://doi. org/10.1037/a0032335

Todorov, A., \& Oosterhof, N. N. (2011). Modeling social perception of faces. Signal Processing Magazine, IEEE, 28, 117-122. https:// doi.org/10.1109/MSP.2010.940006

Tong, F., \& Nakayama, K. (1999). Robust representations for faces: evidence from visual search. Journal of Experimental Psychology: Human Perception and Performance, 25, 1016-1035. https://doi.org/10.1037//0096-1523.25.4.1016

Turner, J. C., Hogg, M. A., Oakes, P. J., Reicher, S. D., \& Wetherell, M. S. (1987). Rediscovering the social group: A self-categorization theory. Basil Blackwell

Van Engen, M. L., \& Willemsen, T. M. (2004). Sex and leadership styles. A meta-analysis of research published in the 1990s. Psychological Reports, 94, 3-18. https://doi.org/10.2466/pr0.94.1. 3-18

Van Vugt, M., \& Grabo, A. E. (2015). The many faces of leadership: An evolutionary-psychology approach. Current Directions in Psychological Science, 24, 484-489. https://doi.org/10.1177/ 0963721415601971

Verosky, S. C., \& Todorov, A. (2010). Generalization of affective learning about faces to perceptually similar faces. Psychological Science, 21, 779-785. https://doi.org/10.1177/0956797610371965

Wang, X., Guinote, A., \& Krumhuber, E. G. (2018). Dominance biases in the perception and memory for the faces of powerholders, with consequences for social inferences. Journal of Experimental Social Psychology, 78, 23-33. https://doi.org/10.1016/j.jesp. 2018.05.003

Watkins, C. D., Fraccaro, P. J., Smith, F. G., Vukovic, J., Feinberg, D. R., DeBruine, L. M., \& Jones, B. C. (2010a). Taller men are less sensitive to cues of dominance in other men. Behavioral Ecology, 21, 943-947. https://doi.org/10.1093/beheco/arq091

Watkins, C. D., Jones, B. C., \& DeBruine, L. M. (2010b). Individual differences in dominance perception: Dominant men are less sensitive to facial cues of male dominance. Personality and Individual Differences, 49, 967-971. https://doi.org/10.1016/j. paid.2010.08.006

Welling, L. L. M., Moreau, B. J. P., Bird, B. M., Hansen, S., \& Carré, J. M. (2016). Exogenous testosterone increases men's perceptions of their own physical dominance. Psychoneuroendocrinology, 64, 136-142. https://doi.org/10.1016/j.psyneuen.2015.11.016

Welling, L. L. M., Persola, L., Wheatley, J. R., Cárdenas, R. A., \& Puts, D. A. (2013). Competition and men's face preferences. Personality and Individual Differences, 54, 414-419. https://doi.org/10. 1016/j.paid.2012.10.014

Wellington, S., Kropf, M. B., \& Gerkovich, P. R. (2003). What's holding women back? Harvard Business Review, 81, 18-19

Wells, G. L., Memon, A., \& Penrod, S. D. (2006). Eyewitness evidence: Improving its probative value. Psychological Science in the Public Interest, 7, 45-75. https://doi.org/10.1111/j.1529-1006.2006. 00027.x

Wheeler, S. C., DeMarree, K. G., \& Petty, R. E. (2007). Understanding the role of the self in prime-to-behavior effects: The active-self account. Personality and Social Psychology Review, 11, 234261. https://doi.org/10.1177/1088868307302223

Wojciszke, B., \& Struzynska-Kujalowicz, A. (2007). Power influences self-esteem. Social Cognition, 25, 472-494. https://doi.org/10. $1521 /$ soco.2007.25.4.472

Wood, W., \& Eagly, A. H. (2012). Biosocial construction of sex differences and similarities in behavior. Advances in Experimental Social Psychology, 46, 55-123. https://doi.org/10.1016/B978-012-394281-4.00002-7

Yap, A. J., Mason, M. F., \& Ames, D. R. (2013). The powerful size others down: The link between power and estimates of others' size. Journal of Experimental Social Psychology, 49, 591-594. https://doi.org/10.1016/j.jesp.2012.10.003

Zell, E., \& Balcetis, E. (2012). The influence of social comparison on visual representation of one's face. PLoS ONE, 7, e36742. https:// doi.org/10.1371/journal.pone.0036742

Publisher's Note Springer Nature remains neutral with regard to jurisdictional claims in published maps and institutional affiliations. 